\title{
PARADIGMA DEL DERECHO A LA SALUD EN LA ACTUALIDAD ARGENTINA
}

MÓNICA ALEJANDRA CANTEROS

FACULTAD DE CIENCIAS ECONOMICAS - UNNE 


\title{
RESUMEN
}

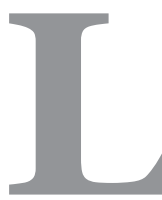

l presente artículo tuvo como objeto describir el estado del arte en el que se encuentra el Derecho a la salud en la actualidad argentina, por medio de la revisión de los paradigmas reconocidos, sostenidos y recogidos en este país en los últimos treinta años.

Este modelo ha sido plasmado en el Proyecto del Nuevo Código Civil y Comercial, hoy en debate.

Tratándose de un trabajo cuyo diseño es de tipo bibliográfico, se buscó como objetivo general describir el paradigma actual del derecho a la salud argentina, tomando como fuentes, la lectura y el análisis de la legislación y doctrina nacional.

Se arribaron a los siguientes resultados: en los últimos treinta años el derecho a la salud tomó expresa jerarquía constitucional, lo que significó el estallido de la legislación protegiendo especialmente al paciente, en búsqueda de una regulación tan protectoria como efectiva. El paradigma vigente, en la Argentina de hoy, resalta la no discriminación y el valor social que tiene el concepto de salud. Destaca derechos personalísimos, como la integridad personal, dignidad, intimidad, muerte digna, y otros derechos como la autodeterminación, derecho a una información sanitaria, libre elección y adhesión a un sistema de salud.

Palabras clave: Salud - Derechos personalísimos - Paciente - Autodeterminación.

\begin{abstract}
This article aimed to describe the state of the art of the Right to health in Argentina today, through the revision of the paradigms that have been recognized, sustained and collected for the last thirty years in this country.

This model has been embodied in the Project of the New Civil and Commercial Code, which is in debate in the present.

Since the design of this investigation belongs to the bibliographic one, the general objective aims to describe the current Argentinian Right to health paradigm.

The results were the following: during the last thirty years, the Right to health became into an explicit constitutional status, which led to the legislation outbreak, protecting especially the patient, in search of a regulation that is as protective as effective. The current paradigm, in Argentina today, emphasizes the nondiscrimination and the social value that concept of Health has. It highlights personal rights, like personal integrity, dignity, privacy, dignified death, and other rights like selfdetermination, health information, free choice, and adherence to a health system.
\end{abstract}

Keywords: Health - Personal rights - Patient - Self-determination. 


\section{1.-ALCANCES DEL DERECHO A LA SALUD}

Para iniciar este trabajo tomaré un párrafo que considero paradigmático y representativo del significado del Derecho a la salud en la Argentina de hoy, el mismo fue escrito por Mosset Iturraspe Jorge, Clara y Mario, quienes dicen: "Y la vida merece ser vivida con salud, en plenitud de aptitudes y posibilidades. De ahí que quien limita o restrinja este derecho fundamental, obra con ilicitud y merece ser sancionado" (Mosset Iturraspe, J.; Mosset Iturraspe, C. y Mosset Iturraspe, M.R. 2012:77). Según resultados de investigaciones que he realizado considero que el derecho a la salud debe ser definida como un sistema complejo, desde el que se busca promover, mantener y mejorar la salud de la persona, por lo que el estudio desde el punto de vista metodológico y a fin de que abarque todas las variables existentes debería ser enfocado desde la interdisciplinariedad. Esta conclusión deviene de la unidad de análisis central, como es el ser humano.

Cualquiera fuera la definición que considere del derecho a la salud, sea esta más o menos extensa; lo unificaré en el máximo derecho de todo ser humano como es el derecho a la vida, por ser el origen de todos y cada uno de los que veremos a continuación. Derecho a la vida como categoría genérica de derechos fundamentales. En el mismo sentido opina Kipper para quien el derecho a la salud "es considerado como uno de los derechos más relevantes, ya que hace a la dignidad de los hombres, especialmente de quienes padecen de enfermedades, siendo necesario el efectivo cumplimiento de las normas imperativas vinculadas con su protección eficaz"( Kipper, C. M. 1998: 257/259).

El complejo empírico lo da la realidad misma, originada por los sujetos provenientes de una construcción social. Como parte de sus interrelaciones, sus derechos y obligaciones las que resultan de las reglas (normas éticas, morales y jurídicas) creación de esos mismos sujetos sociales. Lo expresado indicará el paradigma de este derecho del siglo XXI, que ha ido mutando al punto de permitir hoy en el nuevo Proyecto de Código Civil y Comercial (aun en análisis) a un menor de trece años disponer respecto a los tratamientos médicos que reciba, situación regulada en el artículo 26. Esta regulación ha sido impensada en la primera mitad del siglo XX al menos en nuestro Derecho.

El derecho a la salud, comprensivo de la "persona individual", la protege desde que es reconocida como tal. Según la legislación vigente empieza desde la concepción misma del nuevo ser, hasta el mismo momento de su muerte. Esto implica que el derecho a la salud atraviesa la totalidad del tiempo de existencia, es decir la existencia misma del sujeto.

En la finalización de los años noventa y principios del año dos mil los avances tecnocientíficos han impactado con más fuerza en la realidad humana, de forma tal, que se ha hecho necesario pensar el derecho y su protección desde otra perspectiva, llevando al legislador a revisar, fuentes y principios generales del derecho. Son tan vertiginosos los cambios tanto como avances o retrocesos para la vida humana que el legislador no alcanza a llevar la norma a la práctica que ya el juez se encuentra con otra realidad que lo interpela y debe resolver.

Desde aquí podemos observar al intentar desenredar este entretejido que se origina con la existencia misma de la persona como ser individual y que se complejiza cuando lo pensamos "con el otro" y más aún si lo ubicamos en el escenario de la vida real frente a situaciones 
y relaciones interpersonales, entre las que se encuentran no solo las personas humanas sino también las jurídicas. Entretejido que contiene variables a tener en cuenta como los medios y recursos necesarios para resolver lo referente a organización, financiamiento, gestión, acceso y utilización de servicios de salud.

No puede dejar de mencionarse como parte de esta complejidad, las políticas que deben llevarse adelante en el estado referido a la salud, el sistema de salud elegido en el país, los prestadores del servicio de salud.

Sumado a lo antes manifestado y como parte de este sistema complejo, siguiendo a Tobar diré también que "La cantidad y variedad de actores y roles determinan la complejidad de los sistemas. Es importante destacar que los objetivos de los actores no siempre están vinculados con la situación o estado de salud de la población y las acciones pueden llegar a ir en detrimento de ellos" ( Tobar, F. 2001: 3).

Los actores de esta interrelación son: el hombre como persona individual, centro de imputación normativa, mirado como aquel que es protegido por ser "naturalmente" el sujeto legitimado a reclamar su derecho a la vida, la integridad física y psíquica, al honor, a una muerte digna; siendo éste único destinatario para quien es creado el sistema. También es la que sostiene el sistema financiero que se traduce en la existencia del servicio de salud.

Asimismo, se suman los individuos como un colectivo, ya sea como usuarios de la prestación de salud privada o pública, como cuando actúan formado un grupo de interés, el caso de las asociaciones de consumidores (las que aparecen como reconocidas constitucionalmente luego de la inclusión de los derechos del consumidor en la Ley 24.240).

El Estado como responsable directo e inmediato de sostener tanto en lo individual como colectivo-social éste derecho, colaborando en el sostenimiento del sistema, dándole un orden de prioridad, legislándolo de acuerdo a los valores y principios de sus habitantes, cumpliendo por mandato del pueblo las normas que hacen efectivos sus derechos. Responsable éste de una de las dimensiones a tener en cuenta para el análisis del sistema de salud según Tobar "Una Política de salud implica la definición de la salud como un problema público en el cual el Estado asume un rol activo y explícito. Definir políticas de salud es decidir qué rol desempeña el Estado en salud" (Tobar, F 23 de agosto 2001: 2).

Las personas jurídicas representadas por organizaciones las que son instrumentos partes que intervienen en este complejo sistema, quienes a través de la prestación del servicio de salud hacen efectiva una parte de este derecho; y personas individuales en su carácter de profesionales que desde su arte y profesión colaboran en lograr “el bienestar" que la Organización Mundial de la Salud al definirlo considera debe tener una persona o grupo de personas.

Otra mirada podría dejarnos ver cómo se entrecruzan e influyen, áreas de estudio como la del derecho privado y público, y dentro de éstos los contratos, los derechos humanos, derechos sociales, derechos económicos. También disciplinas como la sociología, la economía, la filosofía, las ciencias médicas y no olvidemos a la religión, ocupan un lugar que directa o indirectamente inciden en este complejo sistema que nos ocupa. 
Según el Informe del Centro de Estudios para Desarrollo Institucional Documento 77 de Septiembre de 2002, "En muchos aspectos, Argentina tiene un sistema de salud altamente desarrollado en comparación con otros países en vías de desarrollo. La expectativa de vida al nacer es de 71 años, superior al promedio de los países de América Latina y que todos los países de igual nivel de ingreso. La tasa de mortalidad infantil ha disminuido un $45 \%$ desde 1970 y la cobertura de servicios de salud es relativamente buena en todos los niveles de ingreso. La cantidad de médicos (30 cada 10.000 habitantes) y de camas disponibles (4.5 cada 1000 habitantes) es comparable con muchos países desarrollados" (Abuelafia, E.; Berlinski, S.; Chudnovsky, M.; Palanza, V.; Ronconi, L.; San Martín, M. E. y Tommasi, M. 2002).

\section{2.-DEFINICIÓN DEL DERECHO A LA SALUD}

Como lo expresa Mosset Iturraspe, el derecho a la salud está íntimamente ligado al derecho a la vida -vida con salud- en la categoría de los derechos humanos o derechos fundamentales. (Mosset Iturraspe, J. 2011:29).

El Protocolo Adicional a la Convención Americana sobre los Derechos Humanos, en materia de Derechos Económicos, Sociales y Culturales (con jerarquía constitucional, en nuestro país,) establece en su artículo 10 que "Toda persona tiene derecho a la salud, entendida como disfrute del más alto nivel de bienestar físico, mental y social”.

Esto significa que la concepción de un derecho a la salud que solo comprenda la falta de bienestar físico es insuficiente, ya que se ha agregado el bienestar mental y social.

Gil Domínguez define cada uno de los niveles de bienestar; el Físico, integrado este concepto por las cuestiones que hacen a lo biológico. Mental, ya que involucra las cuestiones neurológicas o psíquicas de la persona. Y Social, si bien su existencia no tiene lugar a dudas, el concepto aún es discutido (Gil Domínguez, A. 2011: 9).

Respecto al bienestar social, el mismo derecho positivo, en concreto el artículo 11 del Pacto Internacional de Derechos Económicos, Sociales y Culturales en una primera aproximación reconoce el derecho de toda persona a un nivel de vida adecuado para sí y su familia que incluye alimentación, vestido, vivienda y una mejora continua de las condiciones de existencia. (...) Como otra aproximación se puede vincular a la salud social con el pleno bienestar en el contexto en el que las personas desarrollan su biografía y su plan de vida;... es también la búsqueda del "estar bien" como derivación de bienestar general, desde el hábitat cotidiano, donde la mismidad dimensiona la subjetividad con relación al deseo y al goce (Gil Domínguez, A. 2011:17).

Este derecho sostiene Mosset Iturraspe "Es mucho más que el derecho a no padecer enfermedades o limitaciones físicas o mentales...”( Mosset Iturraspe, J. 2011:30).

Esta protección y la garantía del derecho a la salud se extiende al Estado; así lo ha establecido la Corte Suprema de Justicia de la Nación en el caso "Asociación Benghlensis y otras c/ Estado Nacional” en la que sostuvo “... En tales condiciones se infiere que la protección del derecho a la salud, según esta Corte, es una obligación impostergable del Estado Nacional de 
inversión prioritaria” (Gil Domínguez, A. 2011: 14); se observa así que el Derecho a la salud adquiere el más alto rango en la Pirámide Jurídica, a través no solo del artículo, 75 inciso 22, sino también del artículo 42 de la Carta Magna.

Otro aspecto a tener en cuenta respecto al significado del daño a la salud y que cabe preguntarse, es la afirmación de la doctrina italiana referida a que el daño a la salud es autónomo en relación al daño patrimonial y moral. Esto puede verse en la expresión de Cortés, “...Toda vez que el daño a la salud puso en crisis la idea común de relacionar los perjuicios con las necesidades materiales de la víctima, ligada de manera estrecha, con su subsistencia material y con la producción de bienes fue necesario reemplear tal idea (...); en otras palabras, el daño a la salud, que comprendía la posibilidad de satisfacer necesidades materiales, por ocasionar una incapacidad de producir ganancias, dejo de ser tal, para ser un daño relacionado con el bien salud en sí mismo y con la posibilidad de satisfacer necesidades inmateriales, por el hecho, para el afectado de no gozar de ese bien” (Cortés, En: Mosset Iturraspe, J 2011: 47/48).

\section{3.- LA NORMATIVA EN EL TIEMPO}

A fines del siglo XX y antes de la reforma constitucional del año 1994 (sancionada el 15 de diciembre de 1994 y promulgada el 3 de enero de 1995) los autores consideraron que el derecho a la salud entre una de sus características, era reconocido como un derecho implícito, el mismo se encontraba contenido en el artículo 33 de la Constitución Nacional. Acerca de ello Sagües sostiene que el mismo no figuraba expresamente “...en la Constitución atento a las ideologías entonces vigentes, para las cuales el cuidado a la salud importaba, en principio, una cuestión a atender por cada uno" (Sagües, R En: Hernández, C.A. :2011: 55).

El reconocimiento expreso de parte de la Constitución Argentina se ha logrado con la incorporación de los artículos 41 $41^{1}, 42,75$ inciso 22 que otorga, como ya se ha dicho supra, jerarquía constitucional a los tratados allí transcriptos y el inciso 23 que añade el pleno goce y ejercicio de los derechos reconocidos por esta Constitución y por los tratados internacionales vigentes como la Declaración Universal de los Derechos Humanos, la Convención Americana de los Derechos Humanos (ratificada por Ley 23.054)2, el Pacto Internacional de Derechos Económicos, Sociales y Culturales ${ }^{3}$ (ratificado por Ley 23.313), la Convención sobre los Dere-

\footnotetext{
${ }^{1}$ Artículo 41 Constitución Nacional. "Todos los habitantes gozan del derecho a un ambiente sano, equilibrado, apto para el desarrollo humano..." (concepto amplio de salud).

${ }^{2}$ Este Tratado reconoce en sus artículos 4, 5 y 11. Si tomamos lo establecido por la O.M.S al definir la salud incluiremos a lo dispuesto por el art. 4 cuando señala que toda personal tiene derecho a la vida. El art. 5, toda persona tiene derecho a la integridad persona, y 11 , toda persona tiene derecho a la honra y la dignidad.

${ }^{3}$ Reconoce en su preámbulo la dignidad a todos los miembros de la familia humana y de sus derechos iguales e inalienables Reconoce que estos derechos se desprenden de la dignidad inherente a la persona humana. Reconoce que, con arreglo a la Declaración Universal de Derechos Humanos, no puede realizarse el ideal del ser humano libre, liberado del temor y de la miseria, a menos que se creen condiciones que permitan a cada persona gozar de sus derechos económicos, sociales y culturales, tanto como de sus derechos civiles y políticos.
} 
chos del Niño, quien le reconoce el derecho a la vida (art.6).

La reforma constitucional, expresamente en el artículo 42 en su parte pertinente reza: "Los consumidores y usuarios de bienes y servicios tienen derecho, en la relación de consumo, a la protección de su salud, seguridad e intereses económicos; a una información adecuada y veraz; a la libertad de elección, y a condiciones de trato equitativo y digno.(...)”.

Del conjunto de Leyes de los últimos treinta años, que reglamentan la Norma Constitucional del año 1994 y buscan hacer efectivo el cumplimiento de los derechos a la salud podemos enumerar dentro de las más significativas:

- Ley 23.66o Obras Sociales, promulgada en el año 1989.

- Ley 23.661 Sistema Nacional de Seguro de Salud, promulgada en el año 1989.

- Ley 24.091 Sistema de Prestaciones Básicas en habilitación y rehabilitación integral a favor de las personas con discapacidad, promulgada en el año 1997.

- Ley 24.240 Ley de Defensa del Consumidor y Usuario, promulgada en el año 1995.

- Ley 24.445 Cobertura de Obras sociales para personas infectadas con SIDA, promulgada en el año 1995.

- Ley 24.788 Ley Nacional de lucha contra el alcoholismo, promulgada en el año 1997.

- Ley 25.415 Creación del programa nacional de detección temprana y atención de la hipoacusia, promulgada en el año 2001.

- Ley 25.326 Protección de los datos personales, promulgada en el año 2000.

- Resolución 931 del año 2000 Programa Médico Obligatorio.

- Resolución 201 del año 2002 que crea el Programa Medico Obligatorio de Emergencia.

- Resolución 310/2004, modificatoria de la Res. 201/2000.

- Ley 25.673 Métodos anticonceptivos de carácter no permanente, promulgada en el año 2002.

- Ley 26.061 Protección integral de los derechos de las niñas, niños, y adolescentes, promulgada en el año 2005.

- Ley 26.130 Régimen para las intervenciones de contra concepción quirúrgica, promulgada en el año 2005 .

- Ley 26.396 Trastornos alimentarios, promulgada el año 2008.

- Ley 26.588 Ley celíaca, promulgada en el año 2009.

- Ley 26.529 Derechos del Paciente en su relación con los profesionales o instituciones de salud, promulgada en el año 2009, reglamentada por el Decreto 1089/2012 y reformado por la ley 26.742 .

- Ley 26.657 Ley de Salud mental, promulgada en el año 2010.

• Ley 26.682 Medicina Prepaga, promulgada en el año 2011. 


\section{4.-SISTEMA DE SALUD ARGENTINO}

Nuestro país desde el siglo pasado mantiene los tres subsistemas de salud, los cuales no han cambiado al pasar al siglo XXI; éstos son: El subsistema Público (a cargo de Nación o Provincia), Obras sociales (a cargo de obras sociales nacionales, provinciales y del Instituto nacional de Servicios Sociales para Jubilados y Pensionados-PAMI-); el sub sistema de Obras Sociales (OS), se consolidó como tal en 1970 bajo el gobierno del general Onganía, a través de la Ley 18.610, aunque ya en el año 1857 puede hablarse de las primeras Obras sociales sindicales. El sub sistema de salud Privado (Seguros de salud, Medicinas Prepagas, incluidas las cooperativas y mutuales). Son entes siempre de carácter privado y no son creados por ley o convenio colectivo de trabajo, sino que quedan configurados por un contrato hoy regulados por la Ley 26.682 ${ }^{4}$. Es un subsistema alternativo de la que desarrolla el Estado o la Seguridad Social en el sentido en que ejercitan una actividad privada. Son empresas de intermediación.

En cuanto al financiamiento; las Obras sociales se financian con el aporte de empleados y las contribuciones patronales. Cabe incluirse aquí a la INSSJP la que en el contexto de regulación de las obras sociales sindicales en el año 1971 mediante el Decreto Ley 19.032, concentra a la totalidad de la población pasiva bajo una única cobertura social, universal y obligatoria. Así, se instrumentó el Programa de Asistencia Médica Integral (PAMI).

Los entes privados se financian con aportes de sus asociados o asegurados, según corresponda. Si bien este sistema es el tercero en aparecer lleva ya cuatro décadas de existencia. Y por último el subsistema público, cuyos recursos provienen del sistema impositivo, provee servicios de salud de forma gratuita, que si bien puede ser utilizado por cualquier habitante es destinado a la franja de la población con bajos recursos, los que impiden el acceso a los otros dos sistemas.

La regulación de los prestadores de Servicio de Salud privado, ha significado para los Consumidores y Usuarios del mismo, una lucha, que desde principios de siglo fue ganando espacio a favor del débil jurídico ${ }^{5}$ haciendo explícita en la Ley 26.682, la que fuera sancionada finalmente en el año 2011 luego del fracaso de varios proyectos que perdieron estado parlamentario.

\footnotetext{
${ }^{4}$ A partir de la sanción del Decreto de necesidad y urgencia número 446, que determina que a partir del 1 de enero de 2001 la medicina privada podrá competir con las Obras Sociales sindicales, los integrantes de la Comisión de Salud de la Cámara de Diputados aceleraron las discusiones en torno a un tema que será de vital importancia para el futuro desarrollo del sistema de salud: la regulación de las empresas de medicina prepaga. Esta norma, que ya tiene media sanción en el Senado, se convirtió en el elemento clave dentro del nuevo esquema sanitario impulsado por el gobierno y el Banco Mundial, ya que a través de la misma se podrá controlar con mayor eficiencia al subsector privado, uno de los pasos previos fundamentales para su ingreso al mercado de aportes obligatorios. El proyecto ya tiene media sanción del Senado y la autoría del mismo corresponde a los senadores Enrique Martínez Almudevar (PJ-La Pampa), Antonio Cafiero (PJ-Buenos Aires) y Humberto Salum (UCR-Jujuy).

${ }^{5}$ Los llamamos así, debido a que en esta ocasión la persona se encuentra frente a la falta de salud, ya sea con afecciones en la psiquis o en el cuerpo, lo que los ubica en una situación de debilidad en la relación que entabla con expertos en las ciencias médicas u organizaciones encargadas de prestar el servicio.
} 


\section{5.-LOS DERECHOS DEL PACIENTE}

A fin de iniciar este apartado tomaré lo expresado por Mosset Iturraspe para quien "el “daño a la salud" es una especie o hipótesis del "daño a la persona”, a la persona humana, con autonomía del daño patrimonial y también del daño moral,...” ( Mosset Iturraspe, J.2011-3: 3).

Esto nos lleva a un espacio en el que el individuo entre sus tantas situaciones frente a su propia vida se encuentra concretamente ante el Estado en primer lugar; las personas jurídicas que le brindan prestación a su salud y directamente frente al profesional que en el ejercicio de su juramento hipocrático manifiesta "SI FUERA FIEL a este juramento y no lo violara, que se me conceda gozar de mi vida y de mi arte, y ser honrado para siempre entre los hombres. Si lo quebrantara y jurara en falso, que me suceda lo contrario".

Este conjunto de derechos hasta el año 2009 significó para los operadores jurídicos a fin de la defensa de sus clientes, la búsqueda de la justicia, tener que recurrir a principios generales del derecho, leyes especiales, jurisprudencias y algunas normas constitucionales. Recién con la Ley 26.529 se pudo reunir en un solo cuerpo temas que hacía muchos años necesitaban ser regulados con claridad, de manera precisa y contemplando la relación médico-paciente e institución prestadora de servicios de salud-paciente.

Dentro de los alcances de la ley se encuentran temas como el del consentimiento informado, asentimiento unilateral del paciente o su representante legal; aceptación o rechazo a tratamientos, procedimientos médicos o biológicos; derecho a la asistencia médica; trato digno y respetuoso; derecho a la intimidad del paciente y el correlativo deber de confidencialidad de sus datos; derecho a la información clara, precisa y adecuada; a la interconsulta médica.

Algunas ausencias en la ley: la regulación de un sistema legal para accionar, fundada esta idea en las situaciones de gravedad, de amparo e inmediatez para resolver casos que tengan como reclamo la salud del hombre, en especial cuando consideramos que el uso de tecnología de ultima generación implican altos costos. No se ha incluido un tema tan preciso y conflictivo como es el suministro de medicamentos.

\section{6.-NUEVO PROYECTO DE CÓDIGO CIVIL Y COMERCIAL}

La Comisión integrada por los doctores Ricardo Luis Lorenzetti, como Presidente, y Elena Highton de Nolasco y Aída Kemelmajer de Carlucci, en cumplimiento de los objetivos y plazos señalados por el Decreto presidencial 191/2011, presentaron el "Anteproyecto de Código Civil y Comercial de la Nación”.

Este apartado busca no dejar fuera del estudio el conjunto de normas que es objeto de reflexión y análisis en la sociedad y los miembros integrantes del campo jurídico en la actualidad. Buscó solo hacer referencia a aquellos artículos que regulan cuestiones con consecuencias directas en los derechos a la salud. 
La Comisión ha reconocido que en la esfera individual personal hay un amplio reconocimiento de los derechos personalísimos, haciéndolo, a través del valor de la autodeterminación en intereses atinentes a la esfera vital de la persona, los que en el Código encontramos como: actos de disposición sobre su propio cuerpo, investigaciones médicas con personas humanas, consentimiento informado por actos médicos, directivas médicas anticipadas las que son contempladas en los artículos 56, 58, 59 y 60 del Proyecto.

El Proyecto no solo reconoce y protege el Derecho a la Salud de manera individual sino también aquellos casos en que se afecten intereses colectivos (art. 14 ${ }^{6}$ ).

Si tomara los casos de jurisprudencia en materia de Salud, reconocido como un derecho de incidencia social se verá que es cada vez mayor el número en los que por los medios constitucionalmente previstos son defendidos derechos de afección a la salud con incidencia colectiva.

\section{7.-PRESENCIA DE LAS LEGISLACIONES ESPECIFICAS EN EL PROYECTO DE CÓDIGO CIVIL Y COMERCIAL}

Este apartado solo busca ilustrar al lector de alguna normativa que directa o indirectamente influye en el derecho a la salud.

El proyecto transcribe, y en algunos casos amplía la protección ya otorgada en la ley específica en los siguientes artículos: 17, 26 y 32 en cuanto a la restricción a la capacidad o incapacidad para personas con problemas en su salud mental y los artículos 56, 58, 59 y 60 que regulan directamente la autonomía de la voluntad del paciente.

Dentro del Título Preliminar en el Capítulo 4 que refiere a las reglas que confieren una significación general a todo el Proyecto de Código, hallamos en el artículo 17 que regula: "Los Derechos sobre el cuerpo humano. Los derechos sobre el cuerpo humano o sus partes no tienen un valor económico, sino afectivo, terapéutico, científico, humanitario o social, y sólo pueden ser disponibles por su titular cuando se configure alguno de esos valores y según lo dispongan leyes especiales".

Como puede leerse queda expresamente plasmada en la norma el valor que los miembros redactores del proyecto, quienes siguieron los antecedentes de la doctrina, jurisprudencia nacional y del derecho comparado, otorgan al cuerpo humano, sus partes y su psiquis; corroborando la idea sobre el valor que le dan al cuerpo humano como un bien sin valor económico.

El Proyecto, que busca plasmar tratados con jerarquía Constitucional al mismo, y regula de forma expresa la capacidad de ejercicio de la persona menor de edad en lo relativo al cuidado de su propio cuerpo, siguiendo reglas generales aceptadas en el ámbito de la bioética y en el dere-

\footnotetext{
${ }^{6}$ ARTÍCULO 14.- (1) Derechos individuales y de incidencia colectiva. En este Código se reconocen:

a) derechos individuales;

b) derechos de incidencia colectiva.

La ley no ampara el ejercicio abusivo de los derechos individuales cuando pueda afectar al ambiente y a los derechos de incidencia colectiva en general.
} 
cho comparado, que han desarrollado en forma exhaustiva la noción de autonomía progresiva, diferenciándola de la capacidad civil tradicional.

La novedad en lo relacionado con el Derecho a la salud lo encontramos en el párrafo cuarto y quinto del artículo 26 cuando expresa:

Artículo 26.- Ejercicio de los derechos por la persona menor de edad.

(...)

"Se presume que el adolescente entre trece (13) y dieciséis (16) años tiene aptitud para decidir por sí respecto de aquellos tratamientos que no resultan invasivos, ni comprometen su estado de salud o provocan un riesgo grave en su vida o integridad física.

Si se trata de tratamientos invasivos que comprometen su estado de salud o está en riesgo la integridad o la vida, el adolescente debe prestar su consentimiento con la asistencia de sus progenitores; el conflicto entre ambos se resuelve teniendo en cuenta su interés superior, sobre la base de la opinión médica respecto a las consecuencias de la realización o no del acto médico.

A partir de los dieciséis (16) años el adolescente es considerado como un adulto para las decisiones atinentes al cuidado de su propio cuerpo."

El capítulo 3 trata sobre los Derechos y Actos personalísimos que corresponde, del Título I Persona Humana construye según Lorenzetti una esfera de la individualidad personal en aspectos como el amplio reconocimiento a los derechos personalísimos y el valor otorgado a la autodeterminación con relación a los intereses atinentes a la esfera vital de la Persona, en el marco axiológico de la dignidad humana. Normas estas que se inscriben en una fuerte tradición humanista.

Respecto a los derechos de los pacientes, regulada por la Ley 26.529 y que fuera promulgada en el año 2009, la misma ha tratado cuestiones como el vínculo paciente-médico, los actos de disposición sobre el propio cuerpo, el consentimiento informado para médicos, las directivas médicas anticipadas e investigación en salud humana. La ley se ve plasmada en sus generalidades dentro del Proyecto de Código en los artículos 56, 58, 59 y 60.

Este proyecto incluye la relación médico-paciente implícitamente en el texto del Proyecto de Código, situación no hallada en el Código de Vélez.

Puede observarse destacado el "principio de la autonomía de la voluntad", ya que se atiende a los mejores intereses del paciente mirando al enfermo, dejando de lado el valor objetivo de la medicina en cada situación, guiándose por el juicio de valores propio y específico de cada individuo, respetando el derecho del paciente a la autodeterminación, conservando el poder de auto dirigirse. Podemos decir siguiendo también a Galán Cortes que se reúnen tres condiciones: intencionalidad, conocimiento y ausencia de control externo. (Galán Cortés en: Mosset Iturraspe, J. y Piedecasas M.A. 2011: 22).

Artículo 56.- Actos de disposición sobre el propio cuerpo.

Están prohibidos los actos de disposición del propio cuerpo que ocasionen una disminución permanente de su integridad o resulten contrarios a la ley, la moral o las buenas cos- 
tumbres, excepto que sean requeridos para el mejoramiento de la salud de la persona, y excepcionalmente de otra persona, de conformidad a lo dispuesto en el ordenamiento jurídico.

La ablación de órganos para ser implantados en otras personas se rige por la legislación especial.

El consentimiento para los actos no comprendidos en la prohibición establecida en el Primer párrafo no puede ser suplido, y es libremente revocable.

Para hacer mención a la introducción de la investigación en salud humana y el consentimiento informado considero necesario a los fines de abarcar e interpretar el contenido la norma poder definir el significado de los actos médicos. Para Joaquín Ataz López el acto médico "es aquel que solo puede llevar a cabo un médico legitimado, que recae sobre el cuerpo humano vivo o muerto, y que tiene una finalidad curativa directa o indirecta diremos siguiendo. Dentro de los actos indirectos incluimos por ejemplo extracciones de órganos cadavéricos (Ataz López en: Bueres, A 1992: 69).

En el artículo 58 se encuentra la intervención del médico a través de un acto propio de su profesión "El acto de investigación"; la norma no prohíbe las mismas pero sí como condición establece que deben se comprobadas en su eficacia y seguridad, si así no fuera deberán cumplir los requisitos que la misma ley estipula, enumerando así en 7 incisos cuestiones como:

Artículo 58.- Investigaciones en salud humana. La investigación médica en salud humana relativa a intervenciones (tratamientos, métodos de prevención, pruebas diagnósticas o predictivas) cuya eficacia o seguridad no están comprobadas sólo puede ser realizada si se cumplen los siguientes requisitos:

a) ser precedida de una cuidadosa comparación de los riesgos y las cargas para las personas que participan en la investigación en relación con los beneficios previsibles para ellos y para otras personas afectadas por la enfermedad que se investiga;

b) contar con el consentimiento previo, libre, escrito, informado y específico de la persona que se sujeta a la investigación; el consentimiento es libremente revocable;

c) no implicar para el participante riesgos y molestias desproporcionados en relación con los beneficios que se espera obtener de la investigación;

d) asegurar al participante la atención médica pertinente, durante y finalizada la investigación;

e) ser parte de protocolos de investigación para determinar su eficacia y seguridad;

f) contar con la aprobación previa por parte de un comité de evaluación de ética en la investigación;

g) contar con la autorización previa del organismo público correspondiente.

Delimitando lo que se entiende por consentimiento informado o información médica para sobre ella lograr el consentimiento del paciente diremos que: El proyecto se compromete con el derecho de los pacientes definiendo lo que se entenderá por consentimiento informado, y amplia las personas legitimadas para prestar el consentimiento. Sostengo esto teniendo en cuenta que la Ley 26.529 art. 5 no incluye algunas de las personas legitimadas en la declara- 
ción de voluntad. Asimismo el Proyecto amplia en los dos incisos últimos las situaciones en las que el médico debe informar.

Artículo 59.- Consentimiento informado para actos médicos e investigaciones en salud. El consentimiento informado para actos médicos e investigaciones en salud es la declaración de voluntad expresada por el paciente, emitida luego de recibir información clara, precisa y adecuada, respecto a:

a) su estado de salud;

b) el procedimiento propuesto, con especificación de los objetivos perseguidos;

c) los beneficios esperados del procedimiento;

d) los riesgos, molestias y efectos adversos previsibles;

e) la especificación de los procedimientos alternativos y sus riesgos, beneficios y perjuicios en relación con el procedimiento propuesto;

f) las consecuencias previsibles de la no realización del procedimiento propuesto o de los alternativos especificados;

g) en caso de padecer una enfermedad irreversible, incurable, o cuando se encuentre en estado terminal, o haya sufrido lesiones que lo coloquen en igual situación, el derecho a rechazar procedimientos quirúrgicos, de hidratación, alimentación, de reanimación artificial o al retiro de medidas de soporte vital, cuando sean extraordinarios o desproporcionados en relación a las perspectivas de mejoría, o produzcan sufrimiento desmesurado, o tengan por único efecto la prolongación en el tiempo de ese estadio terminal irreversible e incurable;

h) el derecho a recibir cuidados paliativos integrales en el proceso de atención de su enfermedad o padecimiento.

Nadie puede ser sometido a exámenes o tratamientos clínicos o quirúrgicos sin su consentimiento, excepto disposición legal en contrario.

Si el paciente no está en condiciones físicas o psíquicas para expresar su voluntad al tiempo de la atención médica ni la ha expresado anticipadamente, el consentimiento puede ser otorgado por el representante legal, el cónyuge, el conviviente, el pariente o el allegado que acompañe al paciente. En ausencia de todos ellos, el médico puede prescindir del consentimiento si su actuación es urgente y tiene por objeto evitar un mal grave al paciente.

También regulado por la Ley de los derechos del Paciente, los textos se diferencian en cuanto a la manifestación de la voluntad del médico quien en esta Ley 26.529 deberá aceptar. Se repite la prohibición de la posibilidad de autorizar por el propio paciente prácticas eutanásicas, respetando así el grado de evolución y maduración que para la sociedad tiene el tema. Como el reflejo de lo expresado la Suprema Corte de Justicia de la Nación en el Fallo 6-4-93 "Bahamondez, Marcelo" ha dicho "El estado se halla investido de título suficiente para tutelar la integridad física y la vida de las personas en supuestos como el consumo individual de estupefacientes o la práctica de la eutanasia o de operaciones mutilantes carentes de una finalidad terapéutica. En estos supuestos, no existe óbice constitucional para el castigo tanto del afectado como de los profesionales intervinientes, pues constituyen manifestaciones de una cultura 
de la muerte que, al lesionar la naturaleza y la dignidad de la persona, no son susceptibles de tutela ni tolerancia jurídicas (del voto en disidencia de los Dres. Cavagna martinez y Boggiano)" (CSJN, 6-4-93, "Bahamondez, Marcelo", L.L. 1993-D-130, D.J. 1993-2-501).

Artículo 6o.- Directivas médicas anticipadas. La persona plenamente capaz puede anticipar directivas y conferir mandato respecto de su salud y en previsión de su propia incapacidad. Puede también designar a la persona o personas que han de expresar el consentimiento para los actos médicos y para ejercer su curatela. Las directivas que impliquen desarrollar prácticas eutanásicas se tienen por no escritas.

Esta declaración de voluntad puede ser libremente revocada en todo momento por quien la manifestó.

\section{CONCLUSIONES}

Como características del paradigma del Derecho a la salud diré que:

En los últimos treinta años puede observarse un paradigma proteccionista desde el reconocimiento constitucional a los derechos humanos, la que busca la consecuente operatividad de estas normas a través de las regulaciones de ellas en un amplio esquema legislativo que protege al sujeto de derecho, tanto en lo que se refiere a la prevención y asistencia; como sucede cuando es efectiva la búsqueda del estado de salud siendo la falta de bienestar un hecho.

Hoy los derechos de los pacientes son reconocidos como derechos que van más allá del ámbito económico, tratándose conforme lo hemos podido corroborar a lo largo de la exposición de un derecho que por formar parte del ámbito social, busca no solo el bienestar en el aspecto físico, mental sino el bienestar social del individuo, siendo esta una nueva corriente desde el principio de siglo.

Se puede observar una protección especial del llamado por los autores "débil jurídico", quien es más sensible que el propio Consumidor o Usuario de la Ley 24240, ya que los hechos del paciente traspasan el ámbito contractual y entran a otras esferas de la dimensión humana como la del dolor, las sensaciones, tan subjetivas como el bienestar humano.

Respecto al Proyecto de Código Civil y Comercial, de los Juristas Ricardo Luis Lorenzetti, y Elena Highton de Nolasco y Aída Kemelmajer de Carlucci, podemos aportar como una primera mirada al proyecto que ha incorporado en algunos casos de manera expresa y en otros implícitamente derechos que se encuentran embanderados por el Derecho a la salud, los que están teñidos por los principios de autonomía de la voluntad, autodeterminación, según los fundamentos de este Proyecto en búsqueda de la integridad humana, la no discriminación, el derecho a la dignidad.

Este proyecto en lo que refiere al derecho del Paciente, reconoce la autonomía de la voluntad al tomar decisiones que tienen que ver con su bienestar en casos como aceptar o rechazar tratamientos, aceptar o rechazar información, opinar y decidir sobre los riesgos de su salud. Como novedad legislativa la inclusión de la capacidad progresiva de los menores para decidir tratamientos. 
Respecto a los actos Médicos los redactores han incluido al Proyecto expresamente el vínculo médico-paciente, el que no existe en el actual Código Civil.

Las incorporaciones restantes al proyecto han sido normas preexistentes en legislaciones especiales como la Ley de Derecho del Paciente. Destacando la autonomía de la voluntad en la temática desarrollada, como también el derecho a ser informado según puedo interpretar como una manera especial de destacar la debilidad jurídica en que se encuentra el hombre en temas que no forman parte de sus saberes propios. Información que debe ser precisa y clara a fin de que éste ejerza su voluntad a sabiendas y la autodeterminación cumpla los efectos que la norma espera.

No puedo dejar de expresar que estas normas justamente por rozar cuestiones tan íntimamente relacionadas con lo religioso, filosófico, cultural, abren un gran debate, el que esperemos finalmente nos lleve a poner al hombre en el lugar que naturalmente debe tener, delante de toda norma creada por el mismo. Lo que seguramente lograremos si somos capaces de respetar la naturaleza, sus valores y convicciones, pensándola como el de todos y no como individualidades que pueden llevarnos a vivir un desorden social.

\section{REFERENCIAS BIBLIOGRAFÍA}

Abuelafia, E.; Berlinski,S.; Chudnovsky, M.; Palanza, V.; Ronconi,L.; San Martín, M.E. y Tommasi, M. (2002) El funcionamiento del Sistema de Salud Argentino en un contexto Federal. Según el Informe del Centro de Estudios para desarrollo Institucional Documento 77. Recuperado el 03 abril 2010 En: http://faculty.udesa.edu.ar/tommasi/cedi/dts/dt77.pdf

Acuña, Cy Chudnovsky M (Marzo 2002) El Sistema de salud en la Argentina Universidad de San Andrés. Recuperado 24 de septiembre 2012 En: http://estatico.buenosaires.gov.ar/ areas/salud/dircap/mat/matbiblio/salud.pdf

Gil Domínguez, A. (2011) El concepto constitucional de salud como bienestar social de las personas. Revista de Derecho de Daños. Daño a la salud. 2011-3. Buenos Aires: Rubinzal Culzoni Editores.

Hernández, C.A (2011) Algunos aspectos de la Responsabilidad médica por negativa de acceso a la salud (Horizontes e impacto de la ley sobre derechos del paciente) Revista de Derecho de Daños.2011-3. Buenos aires: Rubinzal Culzoni Editores.

Kipper C. M. (1998). Derechos de las minorías ante la discriminación. Buenos Aires: Editorial Hamurabi. 
Mosset Iturraspe, J. (2011) El daño a la salud como denominación feliz del daño a la persona. Revista de Derecho de daños.2011-3 Daños a la salud. Buenos Aires: Rubinzal Culzoni Editores.

Mosset Iturraspe, J.; Mosset Iturraspe, C. y Mosset Iturraspe, M.R (2012) Daño a la Salud. Estudio sobre el Proyecto de Nuevo código Civil y Comercial. Resistencia: Editorial Contexto.

Mosset Iturraspe, J y Piedecasas, M (2011) Derecho del Paciente. Doctrina-Jurisprudencia. (1 ${ }^{\text {a }}$. Edición) Buenos Aires: Rubinzal Culzoni Editores.

Tobar, F (23 de agosto de 2001) Herramientas para el análisis del sector salud. Recuperado el, 11 de octubre de 2011 En: http://www.isalud.com/htm/site/documentos/13_ Archivo_largo.PDF

\section{CURRICULUM VITAE}

\section{MÓNICA ALEJANDRA CANTEROS}

Abogada. Especialista en Docencia Universitaria. Docente e Investigadora categorizada en la Facultad de Ciencias Económicas de la Universidad Nacional del Nordeste. Docente de grado en las asignaturas: Instituciones del Derecho Privado I y Metodología de la Investigación Científica. Docente de Postgrados en áreas Jurídicas, Pedagógicas, Didácticas y de Metodología de la Investigación. Alumna del Doctorado en Ciencias Cognitivas Fac. Humanidades UNNE. Autor de materiales de estudio y publicaciones: capítulos de libros como de artículos científicos en revistas del país y del extranjero. Miembro del Instituto de Ciencias Jurídicas y Sociales de la Academia Nacional de Derecho de Córdoba, en la Región Nordeste.

mcanteros@eco.unne.edu.ar

canterosmonica@gmail.com 